118 | InterAção

\title{
A SAÍDA DO REINO UNIDO DA UNIÃO EUROPEIA: DESCONFIANÇAS HISTÓRICAS E INCERTEAS JURÍDICAS
}

Aurélio Agostinho da Bôaviagem ${ }^{1}$

Jennifer Klein Ferreira de Lima²

\section{Resumo}

Objetiva-se uma análise da União Europeia, através de uma perspectiva histórica e de um estudo do seu processo de integração, estruturado com base na supranacionalidade, com foco na sua relação com o Reino Unido, para fins de delinear as questões que envolvem sua saída do bloco (Brexit) e com a tentativa de vislumbrar as consequências dessa retirada.

Palavras-chave: União Europeia; Reino Unido; Brexit; Tratado de Lisboa; supranacionalidade.

\begin{abstract}
The main goal is the analysis of the European Union through a historical perspective and a study of its integration process, structured on the basis of supranationality, with emphasis on the connection with the United Kingdom, for the purpose of especify the issues related to its exit from the block (Brexit) and with the attempt to foresee the consequences of this withdrawal.
\end{abstract}

Keywords: European Union; United Kingdom; Brexit; Lisbon Treaty; supranationality.

\footnotetext{
${ }^{1}$ Doutor em Direito - Área - Direito Privado - Universidade Federal de Pernambuco - Centro de Ciências Jurídicas (Faculdade de Direito do Recife). Professor vinculado ao Programa de Pós-Graduação em Direito da Universidade Federal de Pernambuco.

2 Especialista em Direito Judiciário e Magistratura do Trabalho (Faculdade Integrada de Pernambuco - FACIPE) e
Mestranda em Direito pelo Programa de Pós-Graduação em Direito da Universidade Federal de Pernambuco,
vinculada à linha de pesquisa "Relações contratuais internacionais".
} 


\section{INTRODUÇÃO}

Em processos de integração regional, os Estados se associam com objetivos eminentemente comerciais e econômicos, com a formação de blocos regionais e de uma estrutura institucional, com a geração de normativas, que passam a requerer do sistema jurídico regional - e principalmente do direito interno de cada Estado - uma tutela específica para cada situação criada.

A União Europeia e o Mercado Comum do Sul (Mercosul) configuram dois importantes Blocos regionais e processos de integração da atualidade. No que tange àquela, verifica-se que sua criação resultou das negociações realizadas entre alguns países europeus no pós-guerra, em virtude da necessidade de reconstrução econômica e de segurança interna frente a ameaças externas.

No caso específico da União Europeia, existe um estreitamento de laços entre os países mais sólido, a partir do momento em que a supranacionalidade foi escolhida como sistema regente de sua estrutura institucional.

Uma organização supranacional pressupõe uma conjugação de interesses em diversos níveis - culturais, sociais, jurídicos, políticos, tarifários, dentre outros, bem como a transferência de competências a órgãos comunitários, cujas normativas passam a ter prevalência perante o direito interno.

Todavia, a mencionada solidez não foi suficiente para evitar o surgimento de problemas advindos do processo de integração e do interrelacionamento entre os Estados membros, bem como não se mostrou capaz de evitar que algum país integrante manifestasse seu interesse em se retirar do Bloco, como o caso do Reino Unido, o qual, cuja participação no Bloco foi tardia, foi o primeiro que requereu, formalmente, a sua saída, mecanismo previsto pelo Tratado de Lisboa, em vigor desde $1^{\text {o }}$ de dezembro de 2009. 
Diante da situação inédita criada pelo Reino Unido, esse estudo tenta delinear algumas situações advindas do Brexit (junção dos seguintes termos em inglês Britain e Exit).

Para fins de melhor explanação do assunto, este trabalho se encontra dividido em partes. Na primeira, serão abordadas generalidades acerca do histórico europeu no período pós-guerra, através da enumeração dos seus tratados institutivos, da sua organização estrutural e das suas peculiaridades no que tange aos modelos de integração econômica. Na segunda parte, serão enfrentadas questões sobre a supranacionalidade no âmbito do Bloco europeu, bem como seus princípios constitutivos e sua relação com a ideia de soberania. $\mathrm{Na}$ terceira parte, serão abordadas as nuances do Tratado de Lisboa e sua aplicação no que tange à retirada do Reino Unido da União Europeia, para fins de delinear as consequências dessa escolha e verificar se o dispositivo legal permissivo da saída consegue prever e resolver todas as questões controversas que possam surgir dessa situação inusitada.

\section{HISTÓRICO DA UNIÃO EUROPEIA: TRATADOS E O PROCESSO DE INTEGRAÇÃO ECONÔMICA}

A conjuntura do processo de integração europeu, com a criação da então União Europeia, encontra-se, temporalmente, em um conturbado período para a história desse continente. De uma forma geral, após o término da Segunda Guerra Mundial, em 1945, a economia dos países europeus restou extrema e negativamente afetada e, com isso, a Europa não pôde mais alcançar a posição de potência mundial, assumida pelos Estados Unidos e pela União Soviética. Em consequência disso, os países europeus foram compelidos a agir, de forma conjunta, para enfrentar os problemas derivados do período bélico e lutar pelo soerguimento de suas economias. 
No início do processo de cooperação econômica entre os países, mais precisamente no ano de 1951, o Bloco europeu contava apenas com os seguintes países: Bélgica, Alemanha, França, Luxemburgo e Países Baixos (União Europeia, países, 2017). Ressalte-se que a União Europeia possui, atualmente, 28 Estados europeus como Estados membros, já incluindo a adesão da Croácia, em 1 de julho de 2013 (UNIÃO EUROPEIA, países, 2017).

Para que seja possível entender o histórico da ação conjunta dos países até alcançar a atual União Europeia, faz-se necessária uma explanação acerca dos Tratados realizados entre os Estados europeus no período pós-guerra.

De início, existia o Tratado que instituiu a Comunidade Europeia do Carvão e do Aço (CECA), de 23 de julho de 1952, que tinha por objetivo minimizar os efeitos negativos advindos da Segunda Guerra Mundial e tornar interdependentes os referidos setores (UNIÃO EUROPEIA, tratados, 2017).

Seguiram-se os Tratados de Roma, datados de 1 de janeiro de 1958, para fins de instituição da Comunidade Econômica Europeia (CEE) e da Comunidade Europeia da Energia Atômica (EURATOM), bem como para firmar uma cooperação econômica entre os países com o consequente aperfeiçoamento da integração europeia (UNIÃO EUROPEIA, Tratados, 2017). Em seguida, pode ser elencado o Tratado de Fusão (Tratado de Bruxelas), de 1 de julho de 1967, para fins de tornar mais simples a atuação das instituições do bloco e para criar uma Comissão e um Conselho únicos para as três Comunidades Europeias até então existentes e acima elencadas (UNIÃO EUROPEIA, tratados, 2017).

Aos Tratados mencionados, pode-se acrescer os seguintess: o Ato Único Europeu, que entrou em vigor em 1 de julho de 1987, objetivando reformas para futura adesão de Portugal e Espanha, bem como simplificação do procedimento de tomada de decisões; o Tratado da União Europeia (Tratado de Maastricht), 
122 | InterAção

que entrou em vigor em 1 de novembro de 1993, com o objetivo de viabilizar a união monetária e criar, formalmente, a União Europeia; o Tratado de Amsterdã, que entrou em vigor em 1 de maio de 1999, com finalidade de modificação das instituições para proporcionar a entrada de mais países (UNIÃO EUROPEIA, tratados, 2017).

Por fim, podem ser listados o Tratado de Nice, que entrou em vigor em 1 de fevereiro de 2003, com a finalidade de modificar a estrutura institucional para que a União Europeia pudesse funcionar com 25 países, e o Tratado de Lisboa, que entrou em vigor em 1 de dezembro de 2009, e que será melhor delineado adiante (UNIÃO EUROPEIA, tratados, 2017).

Em análise à sua organização na contemporaneidade, verifica-se que a União Europeia está estruturada com base na supranacionalidade e em sua evolução no processo de integração entre os países europeus alcançou o modelo de integração econômico denominado de União Econômica e monetária (OCAMPO, 2009, p. 34), que, entretanto, não abarca todos os Estados integrantes do Bloco (UNIÃO EUROPEIA, União econômica..., 2017), ao se considerar que não foram todos os países que adotaram o euro.

Ressalte-se que os modelos de integração econômica podem ser divididos em cinco tipos: zona de livre comércio, união aduaneira, mercado comum, união econômica e integração total, e, a estas cinco etapas, pode-se acrescentar uma sexta, qual seja, a da "zona de preferência ou de intercâmbio preferencial", que representa, como o próprio nome sugere, a existência de uma área em que países, em questões aduaneiras, concedem preferências e um tratamento mais favorável uns aos outros, quando comparadas com aquelas fornecidas a outros Estados que não integram a mesma Zona (OCAMPO, 2009, p. 28). 
Já a Zona de Livre Comércio cuida da criação de uma área comercial em que exista uma comercialização de produtos entre os países com barreiras alfandegárias (tarifárias, bem como as não-tarifárias) reduzidas ou até mesmo inexistentes (BRASIL, Congresso..., 2017).

Por sua vez, em relação à União Aduaneira, que representaria o passo posterior à Zona de Livre Comércio, constata-se que ela pressupõe a existência da chamada Tarifa Externa comum (TEC) (aplicação de uma mesma tarifa para os produtos advindos de países que não pertencem ao respectivo arranjo comercial) (BRASIL, Congresso..., 2017). Brasil, Argentina, Uruguai e Paraguai, dentre outros, através do Mercado Comum do Sul (Mercosul), estão inseridos nesta etapa de integração econômica, apesar de almejarem alcançar a fase de Mercado Comum, a qual está presente na própria denominação deste Bloco (BRASIL, Congresso..., 2017).

No Mercado Comum, etapa mais avançada que as anteriores na busca pela efetiva integração econômica, os países que o integram passam a garantir uma livre circulação não apenas de bens, mas também de pessoas, serviços, capitais e fatores de produção, através de uma coordenação de políticas macroeconômicas e parâmetros equivalentes para fixação de taxas de juros e de câmbio, bem como equivalência da política fiscal (o exemplo desse tipo de fase seria a antiga Comunidade Econômica Europeia, de 1993, quando teria alcançado a etapa de mercado comum) (BRASIL, Congresso..., 2017).

Após, a fase denominada de União Econômica e Monetária, além de pressupor o alcance das etapas anteriores, representa uma integração entre os países através de políticas econômicas e monetárias equânimes, bem como uma moeda única para todos os Estados, da qual a União Europeia seria o maior exemplo (BRASIL, Congresso..., 2017), apesar de a moeda única europeia (euro) não ter sido adotada por todos os países. 
$124 \mid$ InterAção

A etapa denominada de integração total, por sua vez, representaria a última fase do processo de integração entre os Estados, com a superação de questões meramente econômicas, através da adoção de apenas um regime para diversos setores, como o social, o político, o econômico, que só se tornaria possível através de uma estruturação supranacional, cujo exemplo poderia ser o Zollverein alemão (união aduaneira criada em 1834) (OCAMPO, 2009, p. 35-36).

A apresentação das etapas do processo de integração se impôs para que se compreenda a situação atual do panorama europeu, tendo em vista que uma fase seguinte pressupõe a existência e consolidação da anterior.

Nesse sentido, no que tange à evolução do Bloco europeu para uma União econômica e monetária, é ressaltado que "o único exemplo prático desse grau de integração é a União Europeia, onde claramente o processo superou a etapa de integração econômica pura e avançou para áreas como unificação monetária" (OCAMPO, 2009, p 35).

Após essa breve análise acerca das generalidades da União Europeia, passa-se ao deslinde acerca do sistema institucional que rege esse Bloco europeu, tendo em vista sua importância para o fortalecimento de laço entre os países e suas peculiaridades: a supranacionalidade.

\section{O SISTEMA SUPRANACIONAL DA UNIÃO EUROPEIA}

Os processos de integração regidos pelo Direito Comunitário, como a União Europeia, trazem consigo a ideia de uma ordem jurídica supranacional, com a existência de alguns princípios no que tange à sua relação com o direito interno. Passa-se a elencá-los. 
O primeiro deles é a aplicação imediata ou automática da norma comunitária no ordenamento jurídico de cada Estado membro, sendo desnecessárias quaisquer formalidades ou normativas para que isso aconteça, e, dessa forma, as normativas comunitárias passariam a funcionar como se fossem atos legislativos do direito nacional, inexistindo necessidade de interferência dos órgãos do Poder Legislativo para que haja a sua devida aplicação (OCAMPO, 2009, p. 125-127).

Em seguida, enumera-se a existência da aplicação direta da normativa comunitária, no sentido de que produz efeitos jurídicos diretos para os Estados e para os respectivos cidadãos, os quais podem requerer aos juízes nacionais a aplicação dos seus direitos advindos das normativas comunitárias (OCAMPO, 2009, p. 126). Nesse sentido, os magistrados possuem o dever de proceder à sua aplicação. Em outras palavras, de acordo com o Tribunal de Justiça da União Europeia, os atos advindos dos órgãos comunitários do Bloco "emitidos segundo suas normas de procedimento são atos juridicamente perfeitos, exarados sem reservas e não necessitam nenhum ato de um Estado nacional para sua execução e eficácia" (OCAMPO, 2099, p. 126).

O terceiro princípio é o da aplicação das normas comunitárias por juízes nacionais, inclusive para fins de alcançar uma interpretação uniforme do direito comunitário, e, por fim, há a ideia de aplicação predominante ou prevalecente do Direito Comunitário no caso de conflito entre as suas normas e as do direito interno de cada Estado (OCAMPO, 2009, p. 126-127), configurando-se como a suprema garantia de "uniformidade na aplicação do direito comunitário em todos os Estados membros, e é a única forma de garantir eficiência aos órgãos comunitários para o cumprimento das funções e objetivos que lhe foram encomendados" (OCAMPO, 2009, p. 127). 
A enumeração de todos os princípios acima demonstra as características peculiares e marcantes de uma ordem jurídica supranacional, que se faz presente em processos de integração regidos pelo Direito Comunitário.

A importância da especificação e da existência desses princípios reside na necessidade de se estabelecer de forma precisa a relação entre o direito interno e o ordenamento jurídico fruto do Bloco, a fim de que ambos possam coexistir sem a proliferação de diversos conflitos jurídicos que poderiam advir de suas aplicações.

Da supranacionalidade adotada pela União Europeia resulta uma coesão maior entre os Estados e uma estrutura institucional mais complexa que pressupõe a cessão de competências a órgãos comunitários, e a autonomia e independência das instituições do Bloco regional, tornando obrigatórias as suas decisões para os respectivos Estados que o integram.

Entretanto, na União Europeia coexiste a supranacionalidade com a intergovernabilidade, presente nos órgãos em que são discutidas as demandas específicas que não seriam de interesse de todos os Estados membros do Bloco europeu e, nesse sentido, "O sistema intergovernamental compreende os órgãos coletivos onde os Estados concertam as políticas que não são comuns, criando compromissos entre eles na superação de dissonâncias e posições individuais" (LEITE; SANTOS, 2017).

Ademais, há entendimento no sentido de que a supranacionalidade representa um dos conceitos mais difíceis de serem esclarecidos ao se analisar os processos de integração realizados entre países, inclusive porque traz a ideia daquilo que está acima do Estado, e, em consequência disso, a noção de supranacionalidade ensejaria o questionamento acerca de algumas questões, como o conceito de soberania presente no direito internacional clássico, fazendo com que ela pudesse ser vista sob ângulos distintos, como uma soberania 
127 | InterAção

limitada, compartilhada, transferida ou posta em comum, passando a adotar a característica de divisibilidade (OCAMPO, 2009, p. 128).

Compreende-se que a ordem jurídica supranacional "exige a delegação de faculdades constitucionais a órgãos independentes dos governos, para que possam agir com vista à consecução de objetivos comuns" (OCAMPO, 2009, p 130), representando indispensável para a consecução dos seus objetivos a união dos Estados participantes do processo de integração, pois a mera cooperação, sem cessão de competências, não resulta no estreitamento de laços apto à formação de um bloco econômico supranacional.

Tendo em vista essa necessidade de transferência de competências para um órgão comunitário, pode-se imaginar como um dos fatores de resistência à supranacionalidade a ideia de que os interesses nacionais e os interesses supranacionais (da ordem jurídica comunitária) estariam em conflito e que estes prevaleceriam sobre aqueles (OCAMPO, 2009, p. 129).

Nesse sentido, a transferência de competências para os órgãos comunitários não deve ser enquadrada como uma perda de soberania ou anulação dos interesses nacionais, já que estes permanecem, ainda que sob a ótica coletiva, a partir da conjunção das aspirações nacionais de todos os Estados que compõem o processo de integração.

Logo, entende-se que não há o enfraquecimento dos poderes nacionais dos Estados integrantes do processo de integração ao adotarem o sistema institucional da supranacionalidade, mas sim, divisão de atribuições para alcançar fins maiores, até porque qualquer país pode se retirar do Bloco quando desejar, como restou consignado no Tratado de Lisboa, o qual será melhor delineado em tópicos posteriores. 
128 InterAção

\section{O BREXIT: O REINO UNIDO REALMENTE JÁ FEZ PARTE DA UNIÃO EUROPEIA?}

Antes de adentrar nas especificidades normativas do Tratado de Lisboa acerca da saída de algum Estado membro da União Europeia, faz-se necessário conhecer as generalidades das relações do Reino Unido com esse Bloco regional, as quais se mostraram conturbadas desde os primórdios da formação da União Europeia, a fim de que se possa contextualizar o cenário que propiciou a escolha britânica.

A pergunta acima surge a partir de uma reflexão acerca da natureza conturbada da relação entre o Reino Unido, formado pela Inglaterra, pelo País de Gales, pela Escócia (esses três, em conjunto, constituem a Grã-Bretanha), bem como pela Irlanda do Norte e sua adesão ao Bloco europeu se deu em 1 de janeiro de 1973, à época da Comunidade Econômica Europeia (CEE) (UNIÃO EUROPEIA, Reino Unido, 2017).

Desde o início da integração europeia, os britânicos mostraram-se relutantes quanto à entrada no Bloco e, mesmo ao ingressar, não demonstraram sinais plenos de satisfação por participarem do arranjo comercial europeu, por diversos motivos. Dentre eles, pode ser citada a própria estrutura da Comunidade Europeia, que possui normativas próprias, condensadas no seu direito comunitário através da transferência de competências legislativas dos Estados membros para os órgãos comunitários, a partir da ratificação dos respectivos tratados internacionais institutivos do processo de integração (CASTELLO, 2016). E, nesse ponto, “Essa delegação de competência legislativa era um ponto de inconformidade dos britânicos, pois eles percebiam que a UE, ao legislar em nome do Reino Unido, limitava a soberania do país" (CASTELLO, 2016), representando, assim, um receio de participação em um projeto de integração com características supranacionais. 
Nesse sentido, o Reino Unido não integrou de imediato no bloco europeu, passando-se muitos anos para que isso acontecesse, e, em consequência, "foram décadas de ceticismo de políticos e de grande parte da imprensa britânica em relação à União Europeia" (BBC, 2016), sendo que os primeiros esforços para a participação do Reino Unido partiu dos Estados Unidos, inicialmente através do Plano Marshall (1948-1952), e depois da então existente União Europeia de Pagamentos (UEP), iniciada em 1950 e encerrada em 1958 (OLIVEIRA; WOLF, 2016).

O Reino Unido se candidatou a fazer parte da União Europeia em 1961, mas, em virtude da resistência do então presidente francês, Charles de Gaulle, por entender que os interesses desse conjunto de países não estavam de acordo com os do projeto europeu em evolução, a candidatura passou por duas negativas, uma em 1963 e a outra em 1967 (OLIVEIRA; WOLF, 2016). Em 1972, quando não mais aquele presidente ocupava o cargo, e após de muitos esforços de negociação, a candidatura do Reino Unido foi aceita (OLIVEIRA; WOLF, 2016).

Mesmo se associando ao projeto europeu de integração, o Reino Unido não participou de forma satisfatória do CECA, nem do CEE e nem da EURATOM, priorizando as relações que possuíam com outros países, como os Estados Unidos, bem como as suas colônias (OLIVEIRA; WOLF, 2017). Nesse panorama de desinteresse pelo projeto europeu já existente surge a Associação Europeia de Livre Comercio (AELC), em 1960, como uma forma de se insurgir em face da CECA, CEE e da EURATOM, a qual possuía projetos menos ambiciosos em relação aos europeus, com foco na eliminação de barreiras comerciais entre os países em relação a determinados produtos (OLIVEIRA; WOLF, 2017). 
A Associação Europeia de Livre Comercio (ou European Free Trade Association - EFTA) representou o desejo de alguns países que não conseguiram ou não concordavam em transferir competências a um processo de integração supranacional, formalizada através da assinatura, em 4 de janeiro de 1960, da Convenção de Estocolmo, com a respectiva criação de uma zona de livre comércio e tendo como signatários a República Federal da Áustria, a Confederação Helvética, o Reino da Dinamarca, o Reino da Noruega, a República do Portugal, o Reino Unido da Grã-Bretanha e Irlanda do Norte e o Reino da Suécia (OCAMPO, p. 357-358).

A Associação gerou "notável aumento do comércio intrazonal, que quadruplicou durante a década dos 1960", mas mostrou-se insignificante quando em comparação com a União Europeia (OCAMPO, p. 358).

Após a sua entrada no Bloco europeu, os britânicos votaram, então, pela continuação no seio da União Europeia por, dentre outros motivos, concessões deferidas, como a criação do Fundo Europeu de Desenvolvimento Regional (FEDER), em 1975, com o objetivo de estimular o desenvolvimento de algumas regiões do Bloco através de recursos advindos da Comunidade, e com o Acordo de Lomé, de 1975, estabelecido entre a Comunidade Europeia e países subdesenvolvidos (OLIVEIRA; WOLF, 2016). Ressalte-se que, "superado o entusiasmo inicial, a resistência do Reino Unido em relação ao projeto de integração regional europeu voltou a aumentar à medida que ele se tornava mais complexo" (OLIVEIRA; WOLF, 2016).

Apresentadas essas peculiaridades acerca da conturbada relação entre o Reino Unido e a União Europeia, passa-se a delinear o Tratado de Lisboa, utilizado pelo Reino Unido para fundamentar seu requerimento de saída do Bloco. 


\section{O TRATADO DE LISBOA}

O Tratado de Lisboa, que entrou em vigor em 1 de dezembro de 2009, alterou diversos dispositivos dos anteriores Tratado da União Europeia e do Tratado que instituiu a Comunidade Europeia (que passou a ser chamado de Tratado sobre o Funcionamento da União Europeia) (União Europeia, fichas..., 2017).

Dentre as principais contribuições desse Tratado, podem ser citadas as seguintes: modificação nos processos de decisão, com um aumento das funções concedidas ao Parlamento Europeu, inclusive consagrando a possibilidade desse órgão sugerir mudanças nos Tratados, bem como o destaque para a participação e proteção dos respectivos cidadãos, com a consagração de três princípios que são elencados como fundamentais, quais sejam, o da igualdade democrática, o da democracia representativa e o da democracia participativa (União Europeia, fichas..., 2017).

Além desses, podem ser citadas como contribuições do Tratado de Lisboa a previsão, pela primeira vez, das formalidades necessárias para o caso de algum Estado membro desejar se retirar do Bloco, além da atribuição de personalidade jurídica própria para a União Europeia, após a modificação da sua denominação, tendo em vista que deixou de ser chamada de Comunidade Europeia (União Europeia, fichas..., 2017).

Especificamente no que tange à possibilidade de os Estados membros do processo de integração europeu se manifestarem no sentido de não mais permanecer no Bloco, passa-se a elencar o artigo 50 do Tratado da União Europeia (versão consolidada), com a redação proporcionada pelo Tratado de Lisboa: 
Artigo 50.

1. Qualquer Estado-Membro pode decidir, em conformidade com as respetivas normas constitucionais, retirar-se da União.

2. Qualquer Estado-Membro que decida retirar-se da União notifica a sua intenção ao Conselho Europeu. Em função das orientações do Conselho Europeu, a União negocia e celebra com esse Estado um acordo que estabeleça as condições da sua saída, tendo em conta o quadro das suas futuras relações com a União. Esse acordo é negociado nos termos do n. ${ }^{\circ} 3$ do artigo $218 .^{\circ}$ do Tratado sobre o Funcionamento da União Europeia. $\mathrm{O}$ acordo é celebrado em nome da União pelo Conselho, deliberando por maioria qualificada, após aprovação do Parlamento Europeu.

3. Os Tratados deixam de ser aplicáveis ao Estado em causa a partir da data de entrada em vigor do acordo de saída ou, na falta deste, dois anos após a notificação referida no n. ${ }^{\circ}$, a menos que o Conselho Europeu, com o acordo do EstadoMembro em causa, decida, por unanimidade, prorrogar esse prazo.

4. Para efeitos dos n. ${ }^{\circ}$ s 2 e 3, o membro do Conselho Europeu e do Conselho que representa o Estado-Membro que pretende retirar-se da União não participa nas deliberações nem nas decisões do Conselho Europeu e do Conselho que lhe digam respeito.

A maioria qualificada é definida nos termos da alínea b) do $n .{ }^{\circ}$ 3 do artigo 238..$^{\circ}$ do Tratado sobre o Funcionamento da União Europeia.

5. Se um Estado que se tenha retirado da União voltar a pedir a

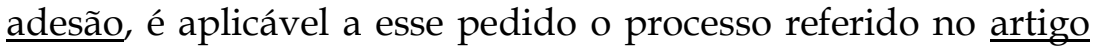
$\underline{49} .{ }^{\circ}$.

(grifos próprios) (LISBOA, Assembleia...)

Em análise ao artigo supracitado, é possível perceber, de início, que, expressamente, é dada aos países a possibilidade de se retirar da União Europeia, de acordo com as disposições das respectivas normas constitucionais. Ou seja, mostra-se que não existe incompatibilidade entre as normas internas de cada Estado integrante do processo de integração e as normas comunitárias, inclusive porque é mencionado que essa saída deve ser realizada em consonância com a Constituição de cada um dos países.

Em seguida, cuida do procedimento para que essa retirada possa ocorrer, a partir da notificação desse desejo a um dos órgãos da União Europeia, qual 
133 | InterAção

seja, o Conselho Europeu. Após, a União Europeia deverá negociar, de acordo com cada caso concreto, um acordo para que fiquem estabelecidos os termos da saída. Nesse sentido, percebe-se que a saída de um Estado membro do processo de integração não resulta nas mesmas condições e consequências para todos que se manifestem pela saída do Bloco.

Essa disposição se faz pertinente a partir do momento em que a situação de cada país será analisada de forma peculiar, de acordo, inclusive, com a influência que cada Estado exerce nas relações jurídicas e comerciais com a União Europeia, tendo em vista que se leva em conta as futuras relações do respectivo país com o Bloco europeu.

Nesse sentido, é esclarecido que a saída deve ser acordada em conformidade com o artigo 218, em seu número 3, do Tratado sobre o Funcionamento da União Europeia, bem como que essa saída comporta três etapas.

Tendo em vista que o dispositivo legal retro transcrito não sinaliza acerca das particularidades econômicas, sociais, comerciais, dentre outras, da saída, restringindo-se às questões formais, podem surgir alguns questionamentos que nele não encontrarão resposta.

Os questionamentos e as dúvidas surgidas acerca da retirada do Reino Unido do Bloco europeu denotam a existência de situações não esclarecidas nas normativas europeias (vigência de dois sistemas jurídicos, o comunitário e o nacional), o que pode causar insegurança jurídica, comercial, política, social.

Nesse sentido, e para dirimir as possíveis dúvidas advindas da situação peculiar criada entre Reino Unido e União Europeia, após a decisão de saída do Bloco por parte do primeiro, a Comissão Europeia disponibilizou na rede mundial de computadores, em 29 de março de 2017, perguntas e respostas 
acerca do transcrito artigo 50 do Tratado da União Europeia (COMISSÃO EUROPEIA, ficha..., 2017).

No que tange aos esclarecimentos presentes no material confeccionado pela Comissão Europeia, três são as etapas para a saída do Reino Unido da União Europeia. Na primeira etapa, são definidas orientações acerca das questões gerais que nortearão o acordo, levando em consideração o interesse comum da União Europeia e dos respectivos Estados integrantes (COMISSÃO EUROPEIA, ficha..., 2017).

$\mathrm{Na}$ segunda etapa, considerando aquelas orientações, o Conselho Europeu recomenda o início às negociações, e, na derradeira etapa, especifica-se que cabe ao Conselho Europeu autorizar o início das negociações com o país que manifestou o desejo de se retirar, com base em uma votação de maioria qualificada, que representaria $72 \%$ dos 27 Estados membros, o que equivaleria a 20 Estados-Membros que representem 65\% da população da União Europeia (COMISSÃO EUROPEIA, ficha..., 2017). Através dessa votação, surgirão diretrizes que nortearão as negociações a serem realizadas pelo chamado negociador da União, que será escolhido pelo Conselho (COMISSÃO EUROPEIA, ficha..., 2017). O negociador-Chefe da União Europeia designado é Michel Barnier (COMISSÃO EUROPEIA, ficha..., 2017).

Após, são elencados questionamentos acerca do negociador da União Europeia, qual será a língua utilizada nas negociações, onde e com que frequência ocorrerão as reuniões, bem como o que aconteceria se não fosse alcançado um acordo (COMISSÃO EUROPEIA, ficha..., 2017).

Seguindo no procedimento formal de saída, o supramencionado artigo 50 estabelece uma situação que pode ser bem prejudicial aos países: a partir do momento em que o acordo entra em vigor, os Tratados referentes à União Europeia não mais serão aplicáveis no âmbito do respectivo Estado, situação 
que também existirá no caso de, dois anos após a notificação de retirada, ainda não existir o acordo de saída. No mais, em caso de necessidade de prorrogação desse prazo de dois anos, é esclarecido que caberá ao Conselho Europeu decidir por uma possível prorrogação, com a anuência do respectivo Estado que se manifestou pela saída.

Considerando que o referido dispositivo do Tratado de Lisboa não procede ao estabelecimento de um elenco detalhado de como se realiza o processo de saída, continua-se fazendo referência ao material elaborado pela Comissão Europeia, sendo nele esclarecido que ao término do período de negociação, o negociador da União formula uma proposta de acordo, a qual será apresentada ao Conselho e ao Parlamento Europeus, considerando, inclusive, a existência de uma relação posterior entre o Reino Unido e União Europeia. Em seguida, o Parlamento procede à aprovação do acordo (por maioria simples) e o Conselho procede à sua conclusão (por maioria qualificada), sendo ressaltado que o Reino Unido, de acordo com suas normas constitucionais, também deve confirmar o acordo (COMISSÃO EUROPEIA, ficha..., 2017).

Percebe-se que o referido artigo, por si só, não esclarece praticamente nenhuma questão substancial acerca da saída, vale insistir, apenas fornecendo indícios que como como se inicia. Isso se torna de certa forma prejudicial porque, especialmente por ser a primeira vez que isso acontece, serão adotadas disposições que não estão expressas no Tratado.

Ressalte-se que há um entendimento no sentido de que, com o Brexit, os britânicos poderão sofrer uma desintegração interna que, dentre outras áreas, afetará de forma substancial o setor social, visto que as consultas populares acerca da saída do Reino Unido do Bloco demonstraram como a sociedade britânica se posicionou de forma diferente sobre o assunto, "sendo que os mais 
ricos, os de maior escolaridade, os mais jovens e os que moram nos centros urbanos optaram pela permanência na UE, [...]"(OLIVEIRA; WOLF, 2016).

\section{CONSIDERAÇÕES FINAIS}

A União Europeia conseguiu evoluir e alavancar o seu processo de integração em aspectos relevantes, tais como estreitamento da relação entre os países, a aceitação e a eficácia das normas regionais. Logo, é possível observar como o arranjo comercial do Bloco europeu possui especificidades, bem como conseguiu ascender a um grau de integração econômica não presenciada, comumente, em outros blocos comerciais.

O alto grau de integração entre os Estados membros da União Europeia reside, também, nas respectivas instituições, com a observação de que o sistema institucional do Bloco Europeu consegue ter um papel essencial no processo de integração, tendo em vista que os respectivos Tratados institutivos e modificativos conferiram funções importante a eles.

Além disso, no âmbito da União Europeia, que adota o sistema institucional supranacional, coexistem aspectos de direitos comunitário, internacional e interno, bem como diferenças culturais, econômicas, sociais, que passam a requerer dos respectivos Estados membros uma coesão forte para que o direito comunitário europeu possa ser aplicado.

Tais circunstâncias, todavia, não se mostraram suficientes para impedir que um país desejasse de retirar do Bloco europeu. Ressalte-se que o Reino Unido, desde o seu ingresso na União Europeia, demonstra sinais de insatisfação, além da diversas tratativas e tentativas para que adentrasse no Bloco anteriormente. Em outras palavras, o Reino Unido adentrou no Bloco, 
mas com desconfianças que fizeram com que, de fato, ele nunca tivesse pertencido à União Europeia, sendo previsível a sua saída.

Com o Brexit, todo o processo de integração europeu, conhecido pela sua estruturação supranacional, complexa e única, com a respectiva coesão entre os países, sentirá os seus efeitos, já que o Reino Unido, dentre outros exemplos, "respondeu por mais de 17\% do PIB comunitário em 2014 - o terceiro maior, depois da Alemanha e da França" (OLIVEIRA; WOLF, 2016), fazendo com que ocorram prejuízos econômicos, sociais e políticos para o Bloco, com a perda de força, interna como internacionalmente (OLIVEIRA; WOLF, 2016).

Pelo exposto, e considerando que o Tratado de Lisboa não elenca todas as especificidades da retirada de um dos membros da União Europeia, somente com a sua conclusão será possível perceber as reais consequências da saída do Reino Unido da União Europeia, restando a esperança mundial para que o procedimento ocorra da forma menos prejudicial possível para os cidadãos britânicos e para a comunidade como um todo.

\section{REFERÊNCIAS}

BRASIL. Congresso Nacional. Comissão Parlamentar Conjunta do Mercosul. Representação Brasileira. Globalização e integração. Disponível em <http:/ / www.camara.leg.br/mercosul/blocos/introd.htm>. Acesso: 20 out. 2017.

BBC. 8 razões pelas quais os britânicos votaram pela saída da União Europeia. 24 jun. 2016. Disponível em: <http://www.bbc.com/portuguese/internacional36609225>. Acesso: 05 nov. 2017.

CASTELLO, Melissa Guimarães. Brexit: a saída do Reino Unido do ponto de vista Jurídico. Conjur. 1 jul. 2016. Disponível em:

<http://www.conjur.com.br/2016-jul-01/melissa-castello-brexit-saida-pontovista-juridico>. Acesso: 05 nov. 2017. 
COMISSÃO EUROPEIA. Ficha informativa. Artigo 50 ${ }^{\circ}$ do Tratado da União Europeia: Perguntas e respostas. Bruxelas. 29 mar. 2017. Disponível em: <europa.eu/rapid/press-release_MEMO-17-648_pt.pdf>. Acesso: 29 out. 2017.

LEITE, Ana Paula Moreira Rodriguez; SANTOS, Thauan. A coexistência da Supranacionalidade e Intergovernabilidade na União Europeia: desafios para a integração. Disponível em:

<http:/ / homacdhe.com/dialogossobredireitoshumanos/wpcontent/uploads/sites/5/2017/02/A-coexist\%C3\%AAncia-dasupranacionalidade-e-intergovernabilidade-na-Uni\%C3\% A3o-Europeiadesafios-para-integra\%C3\%A7\%C3\%A3o.pdf>. Acesso 25 out. 2017.

LISBOA. Assembleia da Republica. Tratado de Lisboa: versão consolidada. Disponível em:

<https://www.parlamento.pt/europa/Documents/Tratado_Versao_Consolida da.pdf>. Acesso: 29 out. 2017.

OCAMPO, Raúl Granillo. Direito internacional público da integração. Rio de Janeiro: Elsevier, 2009.

OLIVEIRA, Giuliano Contento de; WOLF, Paulo José Whitaker. A saída do Reino Unido da União Europeia: um revés civilizatório. Anuario de Integración 13. Año 2016. Disponível em: <http://www.cries.org/wpcontent/uploads/2017/04/009-wolf.pdf>. Acesso: 15 out. 2017.

UNIÃO EUROPEIA. Comissão Europeia. União econômica e monetária. Disponível em:

<http:/ / ec.europa.eu/economy_finance/euro/emu/index_pt.htm>. Acesso: 27 out. 2016.

UNIÃO EUROPEIA. Países. Disponível em: <https:/ / europa.eu/europeanunion/about-eu/countries_pt>. Acesso: 15 out. 2017.

UNIÃO EUROPEIA. Parlamento Europeu. Fichas técnicas sobre a União Europeia. Disponível em:

<http:/ / www.europarl.europa.eu/atyourservice/pt/displayFtu.html?ftuId=F TU_1.1.5.html>. Acesso: 20 out. 2017.

UNIÃO EUROPEIA. Reino Unido. Disponível em: $<$ https://europa.eu/european-union/about-eu/countries/membercountries/unitedkingdom_pt>. Acesso: 29 out. 2017.

UNIÃO EUROPEIA. Tratados da UE. Disponível em: <https:// europa.eu/european-union/law/treaties_pt>. Acesso: 15 out. 2017. 